\title{
Intranasal oxytocin and a polymorphism in the oxytocin receptor gene are associated with human-directed social behavior in golden retriever dogs
}

Mia Persson, Agaia J . Trottier, J ohan Bélteky, Lina Roth and Per J ensen

The self-archived postprint version of this journal article is available at Linköping University Institutional Repository (DiVA):

http:// urn.kb.se/ resolve?urn=urn:nbn:se:liu:diva-142438

N.B.: When citing this work, cite the original publication.

Persson, M., Trottier, A. J ., Bélteky, J ., Roth, L., J ensen, P., (2017), Intranasal oxytocin and a polymorphism in the oxytocin receptor gene are associated with human-directed social behavior in golden retriever dogs, Hormones and Behavior, 95, 85-93.

https:// doi.org/ 10.1016/j.yhbeh.2017.07.016

Original publication available at:

https:/ / doi.org/ 10.1016/j.yhbeh.2017.07.016

Copyright: Elsevier

http:// www.elsevier.com/

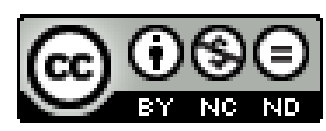




\section{Intranasal oxytocin and a polymorphism in the oxytocin receptor gene are associated with human-directed social behavior in golden retriever dogs}

Mia E. Persson, Agaia J. Trottier, Johan Bélteky, Lina S.V. Roth \& Per Jensen* IFM Biology, AVIAN Behaviour Genomics and Physiology Group, Linköping University, Linköping, Sweden

* Corresponding author: P. Jensen, IFM Biology, AVIAN Behaviour Genomics and Physiology Group, Linköping University, 581 83, Linköping, Sweden. E-mail: perje@ifm.liu.se 


\section{Abstract}

The oxytocin system may play an important role in dog domestication from the wolf. Dogs have evolved unique human analogue social skills enabling them to communicate and cooperate efficiently with people. Genomic differences in the region surrounding the oxytocin receptor $(O X T R)$ gene have previously been associated with variation in dogs' communicative skills. Here we have utilized the unsolvable problem paradigm to investigate the effects of oxytocin and OXTR polymorphisms on human-directed contact seeking behavior in 60 golden retriever dogs. Human-oriented behavior was quantified employing a previously defined unsolvable problem paradigm. Behaviors were tested twice in a repeated, counterbalanced design, where dogs received a nasal dose of either oxytocin or saline 45 min before each test occasion. Buccal DNA was analysed for genotype on three previously identified SNP-markers associated with OXTR. The same polymorphisms were also genotyped in 21 wolf blood samples to explore potential genomic differences between the species. Results showed that oxytocin treatment decreased physical contact seeking with the experimenter and one of the three polymorphisms was associated with degree of physical contact seeking with the owner. Dogs with the AA-genotype at this locus increased owner physical contact seeking in response to oxytocin while the opposite effect was found in GG-genotype individuals. Hence, intranasal oxytocin treatment, an OXTR polymorphism and their interaction are associated with dogs' human-directed social skills, which can explain previously described breed differences in oxytocin response. Genotypic variation at the studied locus was also found in wolves indicating that it was present even at the start of dog domestication.

Keywords: Oxytocin, oxytocin receptor gene, OXTR, domestic dog, canine, wolf, canis lupus, behavior genetics, canine behavior, social behavior

\section{Introduction}

Domestic dogs have apparently evolved unique human analogue communicative skills during the course of domestication and through sharing our ecological niche (Topal et al., 2009). This social competence involves comprehension of 
referential gestures as well as ostensive cues such as pointing and gazing (Lakatos et al., 2012; Soproni et al., 2001). Dogs are e.g. more skillful than both their wolf ancestors and chimpanzees in understanding human communicative behavioral cues during an object choice paradigm (Hare and Tomasello, 1999, 2005). Although primate species have previously been the main focus organisms in comparative social cognition research trying to understand the origin of humans' social skills (Hare et al., 2012), dogs may therefore be equally interesting models.

The differences between dogs and wolves are evident also when studying fully socialised individuals. Wolves do not seek as much human contact as dogs (Gacsi et al., 2009; Topal et al., 2005) and do not use mutual gazing as a mean of communication (Nagasawa et al., 2015). Dogs are able to display intentional referential communicative gestures towards humans, involving both an attention-seeking component as well directional "showing" behaviors (MarshallPescini et al., 2013; Miklosi et al., 2000; Passalacqua et al., 2011). When faced with an unsolvable problem, dogs usually turn to a nearby human for help while wolves do not show this behavior to the same extent (Miklosi et al., 2003). Hence, the evidence suggests that this human-directed social behavior has largely been shaped during domestication.

In spite of the much larger inter-species social competence of dogs, there is still considerable within-breed variation in this trait (Persson et al., 2015). Recent evidence shows that there is a significant genetic basis for this variation: In one population of beagles, the narrow-sense heritability of human-directed social behavior was estimated to 0.23 and candidate genes were identified through genome-wide association analysis (Persson et al., 2015; Persson et al., 2016). Based on its well-established function in social bonding in humans and other mammals (Lim and Young, 2006), it has been suggested that the neuropeptide oxytocin may also play a central role for the unique dog-human bond (Nagasawa et al., 2015). Hence, genetic variations in the oxytocin system may play a role in within- and between-breed differences in human-oriented social behavior and in the bond with the owner (Beetz et al., 2012). 
Oxytocin is produced in the hypothalamus as well as in the periphery and can both act as a neurotransmitter and a neurohormone (Gimpl and Fahrenholz, 2001; Neumann, 2008). Peripheral oxytocin concentrations can increase in both humans and dogs as a result of tactile interaction (Handlin et al., 2011; Mitsui et al., 2011; Odendaal and Meintjes, 2003; Rehn et al., 2014) and mutual gazing (Nagasawa et al., 2009; Nagasawa et al., 2015). However, it has been suggested that it is mainly central and not peripheral oxytocin playing a role in influencing behavior (Leng and Ludwig, 2016). Although the mechanisms are yet poorly understood, peripheral and central (Neumann et al., 2013; Rault, 2016) oxytocin concentrations can be experimentally manipulated though intranasal administration (Leng and Ludwig, 2016), although the increase in central oxytocin upon intranasal administration seems to be small (Rault, 2016).

In spite of this, intranasal administration of this hormone in dogs has been shown to increase positive expectations (Kis et al., 2015), mutual gazing with the owner (Nagasawa et al., 2015), affiliative behavior towards both their owners and conspecifics (Romero et al., 2014), play behavior (Romero et al., 2015) and performance in an object choice task relying on human given pointing cues (Oliva et al., 2015). However, oxytocin does not always have pro-social effects and there seems to be both individual variation and contextual components determining the exact effects of oxytocin (Bartz et al., 2011). For instance, in humans it may decrease trust and cooperation directed towards strangers or members of an out-group (De Dreu, 2012; De Dreu et al., 2010; De Dreu et al., 2011) and in dogs it may decrease friendliness in a threatening situation (Hernadi et al., 2015). Additionally, breed differences have been described in the effects of oxytocin administration (Kovacs et al., 2016a).

Several studies have also reported sex differences in dogs' responses to oxytocin. In females but not in males, intranasal oxytocin administration increased mutual gazing with humans (Nagasawa et al., 2015), looking time in a social motion perception test (Kovacs et al., 2016a) and performance with following human 
ostensive cues (Oliva et al., 2015). Hence, it is important to take both breed and sex into consideration when investigating effects of oxytocin in dogs.

The effects of oxytocin depend both on the hormone levels and the receptor activity. Both oxytocin and the oxytocin receptor (OXTR) are highly conserved and present in mammals as well as several other taxa (Gimpl and Fahrenholz, 2001). In humans, variation in the OXTR gene have e.g. been associated to autism (Jacob et al., 2007), attachment style (Denes, 2015), temperament (Tost et al., 2010), empathy and stress reactivity (Rodrigues et al., 2009). However, variants of the OXTR gene have not yet been as widely studied in dogs.

Among the existing studies, Kis et al. (2014) tested Border Collies and German Shepherds in a battery of social test situations and genotyped them at three different single nucleotide polymorphisms (SNPs) surrounding the OXTR gene. Associations were found between specific SNP genotypes on one hand, and human proximity seeking and friendliness on the other. Interestingly, German Shepherds carrying the A allele of the rs8679684 marker and the G allele of the 19131AG marker were more friendly while the opposite pattern was seen in Border Collies. These results corroborate the importance of taking breed into consideration when investigating oxytocin effects. Another study investigated the effects of genetic variation around OXTR on object choice task performance in pet and shelter dogs of different breeds (Oliva et al., 2016). Although 10 microsatellite markers surrounding the gene were studied, no significant associations were found with task performance. Twelve wolves were also included in the genetic analysis, revealing two genetic markers with significantly different genotype ratios between species.

The contradictive effects of oxytocin on social behavior in both humans and dogs suggest that we are still far from understanding its proper function and mechanism. One possibility is that individuals with different genotypes associated with the OXTR gene respond differently to oxytocin treatment. In humans, OXTR genotypes have been shown to affect the behavioral responses to intranasal oxytocin treatment (Feng et al., 2015; Marsh et al., 2012). To our 
knowledge, the effects of oxytocin depending on genetic variants in the vicinity of OXTR have not yet been examined in dogs.

The aim of the present study was to investigate the effects of intranasal oxytocin treatment, genetic variation in association with OXTR and interactions between hormone treatment and genotype on human-directed social behavior of dogs in the unsolvable problem paradigm. Additionally, given the differences between dogs and wolves in human communicative skills, we also aimed to examine genotypic differences between the species at the same genetic markers surrounding the OXTR gene.

\section{Methods}

\section{Ethical note}

This study protocol was performed in accordance with the ethical permit approved by the regional ethical committee for animal experiments in Linköping, Sweden (permit number: 51-13) with all owners giving their informed consent for their dogs' participation in this study. The methods were carried out in accordance with the relevant guidelines.

\section{Subjects}

Sixty golden retriever dogs (34 females and 26 males) were tested and genotyped to investigate the effects of intranasal oxytocin and OXTR genotype on human-directed social behavior. Owners were recruited to participate in the study through social media, local advertisement and radio. The dogs were required to be registered by the Swedish Kennel Association as purebred golden retrievers, not to be pregnant or lactating and at least 4 months old (mean age of $5.1 \pm 0.47$ years $\pm \mathrm{SE}$; range 4 months -12 years). Buccal samples were collected from the golden retrievers for genotyping of three genetic markers (SNP) associated with the OXTR gene. Additionally, 21 wolf samples ( 7 females and 14 males) were used for genotyping for the same genetic markers. Eighteen wolf blood samples were supplied from Kolmården Wildlife Park, Sweden and three wolf DNA samples previously isolated from brain tissue were originally supplied 
from Borås Animal Park, Sweden. All wolves belong to the Scandinavian population (Canis lupus lupus) and were either raised at the wildlife parks or wild captives.

\section{Procedure}

\section{DNA Sampling}

Buccal samples were collected at the start of the first testing session of each individual, by asking the owner to rub a cotton swab on the inside of their dogs' cheek for approximately 20 seconds. Samples were genotyped for the same three single nucleotide polymorphisms (SNPs) as previously described by Kis et al. (2014) (Fig 1). Sequencing primers for pyrosequencing were designed using the software PyroMark Assay Design 2.0.1.15 by QUIAGEN@. All primers were manufactured by Thermo Fisher Scientific (Waltham, MA, USA) and the sequences can be found in Table 1 .

Table 1: Primer sequences.

\begin{tabular}{ll} 
Primer & Sequence $\left(\mathbf{5}^{\prime} \mathbf{}^{-\mathbf{3}^{\prime} \mathbf{)}}\right.$ \\
\hline 212AG Forward & TACCCCCAACGGGGATTTC \\
212AG Reverse & BIOTIN-GCCCCAGGAACCCCAAGT \\
212AG Sequencing & TGAACAGCACCCCCG \\
rs8679684 Forward & BIOTIN-TTCTCCTGGACCTATCATTTCACT \\
rs8679684 Reversed & GCTTAGAACACTAGGCTTCCACAC \\
rs8679684 Sequencing & GGGTGTTACCAATCCT \\
19131AG Forward & GGGTGTGGAAGCCTAGTGTTCTAA \\
19131AG Reversed & BIOTIN-CCATGCAAAAGTAAAAGCACTCTG \\
19131AG Sequencing & TGGAGGGTGGTGCTA
\end{tabular}

\section{Treatment}

The same two female experimenters (first and second author, referred to in the following as E1 and E2) carried out all the treatments and experiments. Upon arrival at the testing location, each owner was thoroughly informed about the procedure by E1. At the first visit of each individual dog the owner, under supervision of E1, collected the buccal DNA sample. Subsequently, intranasal 
treatment was administered by E1. All dogs were tested at two different occasions (10 \pm 4 days apart). At the first occasion, dogs received either oxytocin or control (saline) treatment. The order of treatments was predetermined, pseudo-randomized and counterbalanced between sexes so that half of the subjects received oxytocin on the first occasion and the other half saline. Treatments were blind to experimenters as well as owners.

Previous studies have administered 12 IU (Kis et al., 2015), 24 IU (Oliva et al., 2015) and 40 IU (Romero et al., 2014) doses of oxytocin, all with significant behavioral effects. Based on this, we decided to use 20 IU in order to be certain to have a biologically potent dose. Intranasal treatments contained either $20 \mathrm{IU}$ oxytocin (04375, Sigma) dissolved in $0.4 \mathrm{ml}$ of phosphate-buffered saline (saline) or $0.4 \mathrm{ml}$ saline only. One half dose $(0.2 \mathrm{ml})$ was administered to each nostril via a Mucosal Atomization Device and a $1 \mathrm{ml}$ syringe. Blinding of treatments was achieved in the following way: E2 prepared the treatment solutions each testing day but these were administered to the dogs by E1. Both E2 and the owners were blind as to which treatment their dogs received at the given occasion. E2 carried out the behavior recordings (see below) but was not provided with the treatment information until after all the video analysis was finished.

\section{Behavior Test}

Behavioral tests were carried out outside, at four different locations in Sweden (Linköping University, SBK Gothenburg, a private kennel outside of Norrköping and at another private kennel outside of Söderköping). The owners brought the dogs to the test site in their own cars, and were told to arrive well before the start of the testing to allow dogs to settle after the transport. Dogs were tested inside a $3 \times 3$ m marquee tent with walls on three sides and without flooring and placed on a short-cut grass lawn. To keep the dogs inside the testing area (the tent) a mesh fence was placed at the open side. Behavioral tests were recorded with an HD camcorder (Canon Legria HF G25) placed on a camera stand approximately $3 \mathrm{~m}$ behind the tent opening. 
After DNA sampling and treatment administration, and before the behavior test, willingness to eat the treats used in the behavioral test was verified by presenting three quarter pieces of Frolic $®$ on a plastic plate of the same material as used in the problem-solving device. A thorough description of the procedure can be found in Persson et al. (2015). All subjects consumed the treats offered within 20 seconds. After the feeding test, owners were asked to walk their dogs for 30 minutes and then let them rest in the car for 10 minutes prior to testing to allow 40-45 minutes to pass between treatment administration and behavioral testing. They were instructed to not treat their dogs differently than usual during the walk but to avoid contact with unknown dogs or humans. If the owner brought more than one dog to the test, the dogs were sampled, treated and tested approximately 5-7 minutes apart.

The problem device used for the behavior tests was the same as previously described by Persson et al. (2015). It consisted of a plastic tray (548 x $248 \mathrm{~mm}$ ) with three symmetrically placed round wells (70 $\mathrm{mm}$ in diameter) covered by transparent plexiglas lids with odour ports. Dog treats (Frolic $®$ ) were placed underneath the three lids. In order to access the treats the dog has to push the lid to the side, however one of the lids was tightly fastened and not possible to open. When the dog and its owner arrived at the testing arena, the unsolvable problem device had already been prepared and placed on the ground $15-30 \mathrm{~cm}$ from the middle of the back wall inside the tent.

Owners had previously been instructed to stand immediately inside the fence in the front right corner of the tent with the dog still on the leash. E2 was standing on the opposite side of the tent in the front left corner. When the fence gate was closed, E2 asked the owner to unleash the dog and as soon as the dog was off the leash E2 started a stopwatch timer and the three minutes of continuous recording started. The dog was allowed to freely move around inside the tent during this time period, however if attempting to escape, the owner was allowed to stop the dog from leaving the tent. Through the testing period, E2 was standing passively facing the problem task and the owner had previously been instructed to do the same. However, if the dog failed to solve any of the solvable 
parts within 60 seconds, E2 opened both solvable lids halfway and immediately walked back to her original position. The testing equipment was cleaned between each subject.

\section{Ethogram and data analysis}

Behavioral analysis was performed from video recordings using The Observer XT 10 software. When owners signed up to participate they supplied the pedigree ID-number, sex and date of birth of the dog. Date and time of testing were also noted. The ethogram used for the behavioral analysis is shown in Table 2. For each behavior described in the ethogram the duration, frequency and latency were recorded.

Table 2: Ethogram of behaviors used in the analysis.

\section{Behavior}

Experimenter zone

Owner zone

Experimenter gaze

Owner gaze

Experimenter physical contact

\section{Description}

Dogs' head is within its own body length of the experimenter

Dogs' head is within its own body length of the owner The dog gaze towards the face of the experimenter The dog gaze towards the face of the owner The dog is in physical contact with the experimenter

Owner physical contact The dog is in physical contact with the owner

\section{DNA extraction and genotyping}

Buccal swabs were stored at $4^{\circ} \mathrm{C}$ and blood/serum samples were stored at $-20^{\circ} \mathrm{C}$ until DNA extraction. From buccal swabs, DNA was extracted from buccal cells using the standard protocol of the Isohelix kit DDK-50. However, the samples were kept in Lysis Buffer and proteinase K for 48 hours prior to continuing with the protocol. Single $50 \mu$ l elisions were used. Wolf samples consisted of 15 full blood samples, three serum samples as well as three samples of previously extracted DNA from brain tissue ready to use in the next step. DNA was extracted from blood and serum samples using the standard protocol of the QIAGEN DNeasy® Blood and Tissue Kit. DNA yield was subsequently quantified using a Nanodrop ND-1000 and stored at $-20^{\circ} \mathrm{C}$ until further use. 
Real-time polymerase chain reaction (qPCR) with subsequent pyrosequencing was used in order to genotype golden retrievers and wolves for each of the three SNP markers. The reaction mixture for the qPCR contained $10 \mu \mathrm{ISYBR}, 5 \mu \mathrm{M}$ each of forward and reverse primer, $2 \mu \mathrm{l}$ DNA template and $6 \mu \mathrm{l}$ water. The qPCR was performed in a Lightcycler@480II Roche at a total volume of $20 \mu \mathrm{l}$ per sample. The program consisted of an initial denaturation at $95^{\circ} \mathrm{C}$ for $10 \mathrm{~min}$, a touchdown protocol with four amplification cycles starting with an annealing temperature of $63{ }^{\circ} \mathrm{C}$, reduced by $1{ }^{\circ} \mathrm{C} /$ cycle to $60^{\circ} \mathrm{C}$. This was followed by 40 cycles of $15 \mathrm{~s}$ denaturation at $95^{\circ} \mathrm{C}, 30 \mathrm{~s}$ annealing at $60^{\circ} \mathrm{C}$ and $30 \mathrm{~s}$ extension at $72{ }^{\circ} \mathrm{C}$. The DNA templates were then subjected to a melting step from $70{ }^{\circ} \mathrm{C}$ to $90{ }^{\circ} \mathrm{C}$ with a $0.1^{\circ} \mathrm{C}$ step increase, each step was held for $2 \mathrm{~s}$.

After DNA amplification, pyrosequencing was performed on the entire $20 \mu \mathrm{l}$ qPCR product volume according to the PyroMark Q24 Vacuum Workstation Quick-Start Guide found at www.quiagen.com. Genotyping results were analysed using the PyroMark Q24 2.0.6 software.

\section{Statistical analysis}

All statistical analysis, except for Hardy-Weinberg Estimates, was carried out using IBM SPSS version 22.0 software. Behavioral data was checked for normality with the Kolmogorov-Smirnov test as well as visually. When necessary data was transformed $(\log 10(\mathrm{x}+1))$. Generalized Linear Mixed Models analysis (GLMM) for repeated measures was used for the statistical analysis. Models consisted of fixed effects of sex, treatment, genotype and the interaction between treatment and genotype. Only the genotype of the 19131AG SNP was analysed as all individuals were fixed for the same genotype at the two other loci. Dog ID was set as a random factor and the data distribution was set to either normal with a link function or gamma with a log function. Factors with the highest $\mathrm{p}$-values were removed from the model if it increased the model fit. Best model fit was determined though comparison of Akaike measurements. Akaike measurements, models and distributions are presented in the Appendix. Bonferroni was used to account for multiple testing. Hardy-Weinberg Estimates (HWE) was calculated 
using the exact test incorporated in the "genetics" package in R. Cohen's $d$ estimates were calculated using $\mathrm{t}$-values from post hoc pairwise comparisons in a web-based effect-size calculator (http://www.campbellcollaboration.org/escalc/html/EffectSizeCalculatorHome.php).

\section{Results}

Genotyping was successful in all 60 golden retrievers and 21 wolves. All samples, both from dogs and wolves, were fixed for the A-allele at the 212AG and rs8679684 SNPs. However, individual variation was found in the 19131AG SNP in both golden retrievers (HWE $p=0.38$ ) and wolves (HWE $p=0.12$ ). Genotype frequencies are displayed in Figure 2. Final statistical models, means and pvalues for all behaviors can be found in the Appendix.

Intranasal oxytocin administration significantly decreased the frequency of experimenter physical contact seeking (Fig 3a; $\mathrm{F}_{1,118}=6.53$, $\mathrm{p}<0.01$ ). No significant effects of oxytocin administration were found for any of the behaviors directed towards the owner.

Independent of treatment, the 19131AG genotype had a significant effect on the latency to owner physical contact $\left(\mathrm{F}_{2,117}=7.17, \mathrm{p}<0.01\right)$ where AA individuals sought contact earlier than AG and GG dogs (Figure 4). There was no effect of the marker genotype on social behavior towards the experimenter.

Treatment and genotype showed a significant interaction effect on the frequency of owner physical contact $\left(\mathrm{F}_{2,113}=5.21, \mathrm{p}<0.01\right)$ where dogs with AA genotype increased contact frequency after oxytocin treatment while GG genotypes showed the opposite reaction (Fig 5a). Treatment and genotype did not have an overall significant effect on duration of owner physical contact. However, there was a significant effect of treatment within individuals carrying the GG-genotype (Figure 5b; Bonferroni adjusted $\mathrm{p}=0.02$, Cohen's $d=0.61$ ). There were no significant interaction effects for behavior directed towards the experimenter. 
Sex significantly affected duration $\left(\mathrm{F}_{1,118}=5.13, \mathrm{p}=0.03\right)$ and frequency $\left(\mathrm{F}_{1,118}=\right.$ $7.85, \mathrm{p}<0.01$ ) of experimenter gaze, where females were seeking more eye contact. Male dogs spent significantly more time than females in the owner zone $\left(\mathrm{F}_{1,118}=4.30, \mathrm{p}=0.04\right)$.

An effect of treatment order was found on the duration of experimenter physical contact $\left(\mathrm{F}_{1,117}=4.87, \mathrm{p}=0.03\right)$ where dogs receiving oxytocin treatment at the first occasion had less physical contact across both trials. Testing occasion also had effects on some human-directed behaviors. Regardless of treatment (oxytocin or saline), at the second test occasion, dogs spent more time in the experimenter zone $\left(F_{1,117}=9.91, p<0.01\right)$, and were in the experimenter zone more frequently $\left(\mathrm{F}_{1,117}=6.29, \mathrm{p}<0.01\right)$ than at the first occasion. They also showed longer duration of experimenter gazing $\left(F_{1,117}=19.10, p<0.00\right)$, higher frequency of the same $\left(\mathrm{F}_{1,117}=24.70, \mathrm{p}<0.00\right)$, and increased frequency of owner gazing during the second test occasion $\left(\mathrm{F}_{1,117}=8.42, \mathrm{p}<0.00\right)$.

\section{Discussion}

This study investigated the effects of intranasal oxytocin administration and a polymorphism associated with the oxytocin receptor gene, OXTR, on humandirected social behavior in golden retriever dogs. We found that administration of oxytocin had significant effects on contact seeking behavior and genotype was found to be associated with some of this behavioral variation. There was also a significant treatment $x$ genotype interaction. Furthermore, we found a similar polymorphism in wolves, indicating that the genetic variation related to OXTR may have been present already in the ancestors of domestic dogs.

We genotyped three different SNPs closely associated with the OXTR gene and previously found to be polymorphic in some dog breeds. Whereas both wolves and golden retrievers had genotypic variation in one and the same of the three studied SNPs (19131AG), they were all fixed for the A-allele at the 212AG and rs8679684 locus that have been shown to vary in other breeds (Kis et al., 
2014) (see also preliminary data in the supplementary material of Kovacs et al. (2016b)). This could indicate that the 212AG and rs8679684 polymorphisms have appeared after the historical split between dogs and wolves. These SNPs could therefore be associated to genomic changes affecting the OXTR gene appearing during dog domestication, possibly even targeted by selection.

At the 19131AG locus, golden retrievers mostly carried the GG and AG genotypes while wolves either had the AA or AG genotype. The fact that we found genetic variation in both golden retrievers and wolves at the same locus suggests that this polymorphism was already present among wolves prior to dog domestication. Although none of the wolf samples carried the GG genotype, this may be a result of small sample size of 21 individuals. The presence of AG individuals shows that the G-allele is present within the wolf population but is probably not as common as the A-allele. Similar to our results, Kis et al. (2014) found that the G-allele was more common among Border Collies where it was almost fixed within the Hungarian population. However, German Shepherds, like the wolves in our studies, mostly carried the AA or AG genotype. It therefore appears that OXTR-related polymorphisms vary between breeds, which may possibly be linked to selection during domestication and modern breeding of purebred populations, selected for different behavioral traits. This corroborates suggestions by (Oliva et al., 2016), who found significant breed differences in allele distribution of microsatellites surrounding the OXTR in different breeds and wolves.

In the present study, oxytocin treatment alone affected how dogs were seeking physical contact from a previously unknown experimenter. There is evidence of oxytocin playing a significant role in the social bond between dogs and their owners (Nagasawa et al., 2009; Nagasawa et al., 2015; Romero et al., 2014). Although oxytocin is mostly known to enhance social behavior (Carter, 2014), in this case, dogs in fact sought less contact with the experimenter upon oxytocin administration. This is in agreement with previous research showing that intranasal oxytocin treatment does not always have pro-social effects in either humans (Bartz et al., 2011; De Dreu, 2012) or dogs (Hernadi et al., 2015). This 
could be due to a contextual as well as an individual factor affecting the effects of oxytocin (Bartz et al., 2011). There is also recent evidence of breed differences in oxytocin response. Kovacs et al. (2016b) found that intranasal oxytocin administration increased gazing towards an experimenter in Border Collies but decreased the same behavior in Siberian Huskies. The authors suggest that genetic differences between breeds may cause these differences.

Oxytocin is not believed to pass the blood-brain barrier in significant amounts (Leng and Ludwig, 2016). There are studies showing that intranasal administration of oxytocin can increase central oxytocin slightly (Leng and Ludwig, 2016; Rault, 2016). However, there are also studies finding no increase (Leng and Ludwig, 2016). In spite of this, several studies have measured behavioral effects of peripheral oxytocin administration in dogs, although the mechanisms are still unknown. E.g. exogenously administrated oxytocin has been shown to increase dogs' positive expectations (Kis et al., 2015), social play behaviour (Romero et al., 2015), following of human ostensive cues (Oliva et al., 2015), affiliative behaviors towards both humans and conspecifics (Romero et al., 2014) and mutual gazing with the owner (Nagasawa et al., 2015). Additionally, behaviors such as dog-owner interaction and reunion can increase peripheral oxytocin levels (Handlin et al., 2011; Rehn et al., 2014).

Similar to Kis et al. (2014), we found that the individual genotype of the OXTR 19131AG polymorphism is associated with human-directed social behavior in dogs. They also identified a breed effect where German Shepherds carrying the A-allele scored higher on friendliness while the opposite effect was found in Border Collies. In our case, golden retrievers with the AA genotype had a significantly shorter latency to seek physical contact from their owner. Oliva et al. (2016) did not find any associations between genomic differences and object choice task performance. However, this could be due to the fact that they studied a group of mixed breeds while Kis et al. (2014) demonstrated that OXTR gene polymorphisms could have opposing effects in different breeds. Another reason could be that they investigated microsatellites further away from the OXTR-gene than the three previously known polymorphisms. 
Considering the opposing effects of oxytocin, OXTR-SNP variants and breed interactions on dogs' human-directed social behavior, it is reasonable to assume that individuals with different OXTR-SNP variants respond differently to oxytocin administration. We found that golden retrievers carrying the AA genotype of the 19131AG SNP sought more physical contact from their owners upon oxytocin treatment while GG individuals reacted in the opposite direction and no differences were found in heterozygotes. In humans, OXTR-gene variants have been shown to modulate the effect of intranasal oxytocin treatment. Feng et al. (2015) found that oxytocin increased the brain response to reciprocal behavior in men with the GG genotype of one polymorphism (rs53576) while the opposite effect was found in women. Additionally, recent research on oxytocin as a treatment for autism spectrum disorder found that its efficiency is dependent on OXTR-gene genotype (Kosaka et al., 2016).

There is increasing evidence of polymorphisms located in non-coding sequences to be associated with behavioral effects (Banlaki et al., 2015; Persson et al., 2016). In our case, the associated polymorphism is located in the 3 ' untranslated region immediately after the last exon of the dog OXTR-gene. Therefore, this variant does not alter the protein coding sequence, but serves merely as a marker related to any polymorphism in linkage disequilibrium (Schaub et al., 2012). Since the included markers have been associated with behavior phenotypes they should be associated with close-by genomic differences possibly affecting the OXTR-gene.

Although it is highly unlikely that 19131AG in fact is a causative SNP altering dogs' human-directed social behavior, we can not exclude a possible involvement in gene regulation. Non-coding polymorphisms in the 3' untranslated region can affect microRNA binding and affect gene expression (Kovacs-Nagy et al., 2013; Zhao et al., 2013). Additionally, non-coding genetic variation such as intronic polymorphisms can alter splicing (Lalonde et al., 2011) and have a long-distance effect on gene regulation (Maurano et al., 2012; Visser et al., 2012). Hence, we cannot exclude the possibility that the 19131AG SNP has a causal behavioural 
effect on dog behaviour. However, it is important to note that this study merely shows a trait association and the SNP most likely reflects other close-by genomic differences.

We found that female golden retrievers sought significantly more human eye contact than males. This is in agreement with previous results showing that human-directed social behavior in dogs differs between sexes where females seek more physical contact from humans than males (Persson et al., 2015; Roth and Jensen, 2015). Also, oxytocin treatment has been shown to have different sex dependent effects on human directed gazing, increasing looking behavior in females (Kovacs et al., 2016a; Nagasawa et al., 2015; Oliva et al., 2015). In this study, males and females did not differ in their response to the oxytocin treatment. Also, no effects of sex and genotype were shown. However, this could be due to the fact that there were only four males and four females with the AAgenotype. To identify such effects one would need to study a larger population or a population with more evenly divided genotypes.

Our dogs were tested in a repeated measures design, so half of the individuals received oxytocin treatment at the first testing occasion and saline control treatment at the second. Somewhat unexpected, we found that dogs receiving oxytocin at the first testing occasion sought less experimenter physical contact across both trials. Test order also had an effect independent of treatment where dogs sought more contact with the experimenter at the second occasion. Experiences of the experimenter at the first visit may therefore have influenced their social behavior at the second occasion. This shows that factors such as treatment order and testing occasion are important to take into consideration when planning a repeated measures design for investigating effects of oxytocin on dog social behavior.

\section{Conclusions}

This is to our knowledge the first study to report different effects of oxytocin treatment associated with an OXTR polymorphism in dogs. We have shown that some of the opposing breed specific effects of oxytocin treatment found in other 
studies could be a result of OXTR-SNP variation. We have also presented the genotype frequencies of three previously known SNPs in one novel dog breed, the golden retriever, and a novel species, the wolf (Canis lupus lupus). By doing so, we have contributed to an increased knowledge of OXTR-polymorphism frequencies across dog breeds but also through the domestication process from wolf to dog.

\section{Acknowledgements}

We are grateful to all the owners and their dogs participating in this study. A special thanks to SBK Gothenburg for letting us arrange testing around their facilities. This project was funded by the European Research Council (ERC) within the advanced grant 'GENEWELL' (322206).

\section{References}

Banlaki, Z., Elek, Z., Nanasi, T., Szekely, A., Nemoda, Z., Sasvari-Szekely, M., Ronai, Z., 2015. Polymorphism in the serotonin receptor 2a (HTR2A) gene as possible predisposal factor for aggressive traits. Plos One 10, e0117792.

Bartz, J.A., Zaki, J., Bolger, N., Ochsner, K.N., 2011. Social effects of oxytocin in humans: context and person matter. Trends in cognitive sciences 15, 301-309. Beetz, A., Uvnas-Moberg, K., Julius, H., Kotrschal, K., 2012. Psychosocial and psychophysiological effects of human-animal interactions: the possible role of oxytocin. Front Psychol 3, 234.

Carter, C.S., 2014. Oxytocin pathways and the evolution of human behavior. Annu Rev Psychol 65, 17-39.

De Dreu, C.K., 2012. Oxytocin modulates cooperation within and competition between groups: an integrative review and research agenda. Horm Behav 61, 419-428.

De Dreu, C.K., Greer, L.L., Handgraaf, M.J., Shalvi, S., Van Kleef, G.A., Baas, M., Ten Velden, F.S., Van Dijk, E., Feith, S.W., 2010. The neuropeptide oxytocin regulates parochial altruism in intergroup conflict among humans. Science 328, 1408-1411. De Dreu, C.K., Greer, L.L., Van Kleef, G.A., Shalvi, S., Handgraaf, M.J., 2011.

Oxytocin promotes human ethnocentrism. Proc Natl Acad Sci U S A 108, 12621266.

Denes, A., 2015. Genetic and Individual Influences on Predictors of Disclosure: Exploring Variation in the Oxytocin Receptor Gene and Attachment Security. Commun Monogr 82, 113-133.

Feng, C., Lori, A., Waldman, I.D., Binder, E.B., Haroon, E., Rilling, J.K., 2015. A common oxytocin receptor gene (OXTR) polymorphism modulates intranasal oxytocin effects on the neural response to social cooperation in humans. Genes Brain Behav 14, 516-525.

Gacsi, M., Gyori, B., Viranyi, Z., Kubinyi, E., Range, F., Belenyi, B., Miklosi, A., 2009. Explaining Dog Wolf Differences in Utilizing Human Pointing Gestures: Selection for Synergistic Shifts in the Development of Some Social Skills. Plos One 4. 
Gimpl, G., Fahrenholz, F., 2001. The oxytocin receptor system: structure, function, and regulation. Physiol Rev 81, 629-683.

Handlin, L., Hydbring-Sandberg, E., Nilsson, A., Ejdeback, M., Jansson, A., UvnasMoberg, K., 2011. Short-Term Interaction between Dogs and Their Owners: Effects on Oxytocin, Cortisol, Insulin and Heart Rate-An Exploratory Study. Anthrozoos 24, 301-315.

Hare, B., Tomasello, M., 1999. Domestic dogs (Canis familiaris) use human and conspecific social cues to locate hidden food. Journal of comparative psychology 113, 173-177.

Hare, B., Tomasello, M., 2005. Human-like social skills in dogs? Trends in cognitive sciences 9, 439-444.

Hare, B., Wobber, V., Wrangham, R., 2012. The self-domestication hypothesis: evolution of bonobo psychology is due to selection against aggression. Anim Behav 83, 573-585.

Hernadi, A., Kis, A., Kanizsar, O., Toth, K., Miklosi, B., Topal, J., 2015. Intranasally administered oxytocin affects how dogs (Canis familiaris) react to the threatening approach of their owner and an unfamiliar experimenter. Behav Processes 119, 1-5.

Jacob, S., Brune, C.W., Carter, C.S., Leventhal, B.L., Lord, C., Cook, E.H., Jr., 2007. Association of the oxytocin receptor gene (OXTR) in Caucasian children and adolescents with autism. Neuroscience letters 417, 6-9.

Kis, A., Bence, M., Lakatos, G., Pergel, E., Turcsan, B., Pluijmakers, J., Vas, J., Elek, Z., Bruder, I., Foldi, L., Sasvari-Szekely, M., Miklosi, A., Ronai, Z., Kubinyi, E., 2014. Oxytocin Receptor Gene Polymorphisms Are Associated with Human Directed Social Behavior in Dogs (Canis familiaris). Plos One 9.

Kis, A., Hernadi, A., Kanizsar, O., Gacsi, M., Topal, J., 2015. Oxytocin induces positive expectations about ambivalent stimuli (cognitive bias) in dogs. Horm Behav 69, 1-7.

Kosaka, H., Okamoto, Y., Munesue, T., Yamasue, H., Inohara, K., Fujioka, T., Anme, T., Orisaka, M., Ishitobi, M., Jung, M., Fujisawa, T.X., Tanaka, S., Arai, S., Asano, M., Saito, D.N., Sadato, N., Tomoda, A., Omori, M., Sato, M., Okazawa, H., Higashida, H., Wada, Y., 2016. Oxytocin efficacy is modulated by dosage and oxytocin receptor genotype in young adults with high-functioning autism: a 24-week randomized clinical trial. Transl Psychiatry 6, e872.

Kovacs, K., Kis, A., Kanizsar, O., Hernadi, A., Gacsi, M., Topal, J., 2016a. The effect of oxytocin on biological motion perception in dogs (Canis familiaris). Animal cognition.

Kovacs, K., Kis, A., Pogany, A., Koller, D., Topal, J., 2016b. Differential effects of oxytocin on social sensitivity in two distinct breeds of dogs (Canis familiaris). Psychoneuroendocrinology 74, 212-220.

Kovacs-Nagy, R., Elek, Z., Szekely, A., Nanasi, T., Sasvari-Szekely, M., Ronai, Z., 2013. Association of aggression with a novel microRNA binding site polymorphism in the wolframin gene. Am J Med Genet B Neuropsychiatr Genet 162B, 404-412.

Lakatos, G., Gácsi, M., Topál, J., Miklósi, Á., 2012. Comprehension and utilisation of pointing gestures and gazing in dog-human communication in relatively complex situations. Animal cognition 15, 201-213. 
Lalonde, E., Ha, K.C., Wang, Z., Bemmo, A., Kleinman, C.L., Kwan, T., Pastinen, T., Majewski, J., 2011. RNA sequencing reveals the role of splicing polymorphisms in regulating human gene expression. Genome Res 21, 545-554.

Leng, G., Ludwig, M., 2016. Intranasal Oxytocin: Myths and Delusions. Biol Psychiatry 79, 243-250.

Lim, M.M., Young, L.J., 2006. Neuropeptidergic regulation of affiliative behavior and social bonding in animals. Horm Behav 50, 506-517.

Marsh, A.A., Yu, H.H., Pine, D.S., Gorodetsky, E.K., Goldman, D., Blair, R.J., 2012.

The influence of oxytocin administration on responses to infant faces and potential moderation by OXTR genotype. Psychopharmacology (Berl) 224, 469476.

Marshall-Pescini, S., Colombo, E., Passalacqua, C., Merola, I., Prato-Previde, E., 2013. Gaze alternation in dogs and toddlers in an unsolvable task: evidence of an audience effect. Animal cognition 16, 933-943.

Maurano, M.T., Humbert, R., Rynes, E., Thurman, R.E., Haugen, E., Wang, H., Reynolds, A.P., Sandstrom, R., Qu, H., Brody, J., Shafer, A., Neri, F., Lee, K., Kutyavin, T., Stehling-Sun, S., Johnson, A.K., Canfield, T.K., Giste, E., Diegel, M., Bates, D., Hansen, R.S., Neph, S., Sabo, P.J., Heimfeld, S., Raubitschek, A., Ziegler, S., Cotsapas, C., Sotoodehnia, N., Glass, I., Sunyaev, S.R., Kaul, R., Stamatoyannopoulos, J.A., 2012. Systematic localization of common disease-associated variation in regulatory DNA. Science 337, 1190-1195.

Miklosi, A., Kubinyi, E., Topal, J., Gacsi, M., Viranyi, Z., Csanyi, V., 2003. A simple reason for a big difference: wolves do not look back at humans, but dogs do. Curr Biol 13, 763-766.

Miklosi, A., Polgardi, R., Topal, J., Csanyi, V., 2000. Intentional behaviour in doghuman communication: an experimental analysis of "showing" behaviour in the dog. Animal cognition 3, 159-166.

Mitsui, S., Yamamoto, M., Nagasawa, M., Mogi, K., Kikusui, T., Ohtani, N., Ohta, M., 2011. Urinary oxytocin as a noninvasive biomarker of positive emotion in dogs. Horm Behav 60, 239-243.

Nagasawa, M., Kikusui, T., Onaka, T., Ohta, M., 2009. Dog's gaze at its owner increases owner's urinary oxytocin during social interaction. Horm Behav 55, 434-441.

Nagasawa, M., Mitsui, S., En, S., Ohtani, N., Ohta, M., Sakuma, Y., Onaka, T., Mogi, K., Kikusui, T., 2015. Social evolution. Oxytocin-gaze positive loop and the coevolution of human-dog bonds. Science 348, 333-336.

Neumann, I.D., 2008. Brain oxytocin: a key regulator of emotional and social behaviours in both females and males. J Neuroendocrinol 20, 858-865.

Neumann, I.D., Maloumby, R., Beiderbeck, D.I., Lukas, M., Landgraf, R., 2013. Increased brain and plasma oxytocin after nasal and peripheral administration in rats and mice. Psychoneuroendocrinology 38, 1985-1993.

Odendaal, J.S., Meintjes, R.A., 2003. Neurophysiological correlates of affiliative behaviour between humans and dogs. Vet J 165, 296-301.

Oliva, J.L., Rault, J.L., Appleton, B., Lill, A., 2015. Oxytocin enhances the appropriate use of human social cues by the domestic dog (Canis familiaris) in an object choice task. Animal cognition 18, 767-775.

Oliva, J.L., Wong, Y.T., Rault, J.L., Appleton, B., Lill, A., 2016. The oxytocin receptor gene, an integral piece of the evolution of Canis familiaris from Canis lupus. Pet Behaviour Science 2, 1-15. 
Passalacqua, C., Marshall-Pescini, S., Barnard, S., Lakatos, G., Valsecchi, P., Previde, E.P., 2011. Human-directed gazing behaviour in puppies and adult dogs, Canis lupus familiaris. Anim Behav 82, 1043-1050.

Persson, M.E., Roth, L.S.V., Johnsson, M., Wright, D., Jensen, P., 2015. Humandirected social behaviour in dogs shows significant heritability. Genes Brain Behav 14, 337-344.

Persson, M.E., Wright, D., Roth, L.S., Batakis, P., Jensen, P., 2016. Genomic Regions Associated With Interspecies Communication in Dogs Contain Genes Related to Human Social Disorders. Scientific reports 6, 33439.

Rault, J.L., 2016. Effects of positive and negative human contacts and intranasal oxytocin on cerebrospinal fluid oxytocin. Psychoneuroendocrinology 69, 60-66. Rehn, T., Handlin, L., Uvnäs-Moberg, K., Keeling, L.J., 2014. Dogs' endocrine and behavioural responses at reunion are affected by how the human initiates contact. Physiology \& Behavior 124, 45-53.

Rodrigues, S.M., Saslow, L.R., Garcia, N., John, O.P., Keltner, D., 2009. Oxytocin receptor genetic variation relates to empathy and stress reactivity in humans. Proc Natl Acad Sci U S A 106, 21437-21441.

Romero, T., Nagasawa, M., Mogi, K., Hasegawa, T., Kikusui, T., 2014. Oxytocin promotes social bonding in dogs. Proc Natl Acad Sci U S A 111, 9085-9090. Romero, T., Nagasawa, M., Mogi, K., Hasegawa, T., Kikusui, T., 2015. Intranasal administration of oxytocin promotes social play in domestic dogs. Commun Integr Biol 8, e1017157.

Roth, L.S.V., Jensen, P., 2015. Assessing companion dog behavior in a social setting. J Vet Behav 10, 315-323.

Schaub, M.A., Boyle, A.P., Kundaje, A., Batzoglou, S., Snyder, M., 2012. Linking disease associations with regulatory information in the human genome. Genome Res 22, 1748-1759.

Soproni, K., Miklosi, A., Topal, J., Csanyi, V., 2001. Comprehension of human communicative signs in pet dogs (Canis familiaris). Journal of comparative psychology 115, 122-126.

Topal, J., Gacsi, M., Miklosi, A., Viranyi, Z., Kubinyi, E., Csanyi, V., 2005. Attachment to humans: a comparative study on hand-reared wolves and differently socialized dog puppies. Anim Behav 70, 1367-1375.

Topal, J., Miklosi, A., Gacsi, M., Doka, A., Pongracz, P., Kubinyi, E., Viranyi, Z., Csanyi, V., 2009. The Dog as a Model for Understanding Human Social Behavior. Adv Stud Behav 39, 71-116.

Tost, H., Kolachana, B., Hakimi, S., Lemaitre, H., Verchinski, B.A., Mattay, V.S., Weinberger, D.R., Meyer-Lindenberg, A., 2010. A common allele in the oxytocin receptor gene (OXTR) impacts prosocial temperament and human hypothalamiclimbic structure and function. Proc Natl Acad Sci U S A 107, 13936-13941.

Visser, M., Kayser, M., Palstra, R.J., 2012. HERC2 rs12913832 modulates human pigmentation by attenuating chromatin-loop formation between a long-range enhancer and the OCA2 promoter. Genome Res 22, 446-455.

Zhao, X., Ye, Q., Xu, K., Cheng, J., Gao, Y., Li, Q., Du, J., Shi, H., Zhou, L., 2013. Singlenucleotide polymorphisms inside microRNA target sites influence the susceptibility to type 2 diabetes. J Hum Genet 58, 135-141. 
OXTR

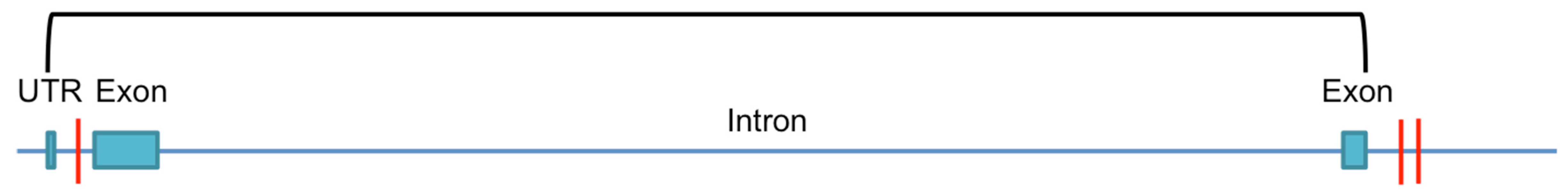


A) Golden

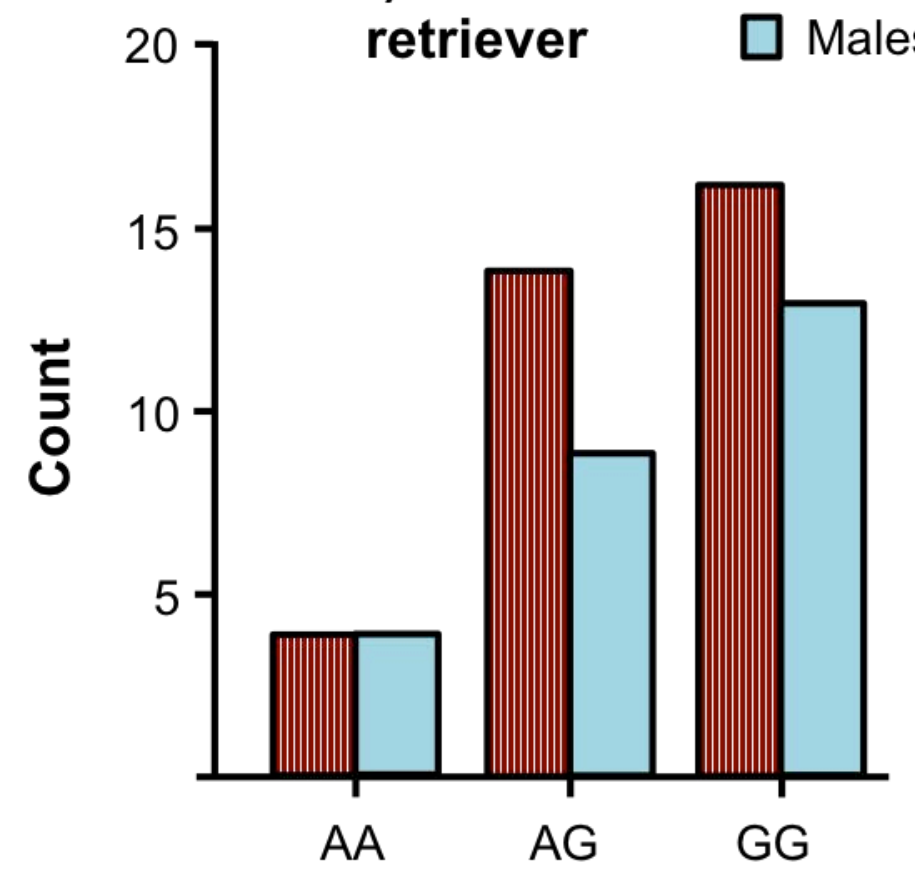

B) Wolf

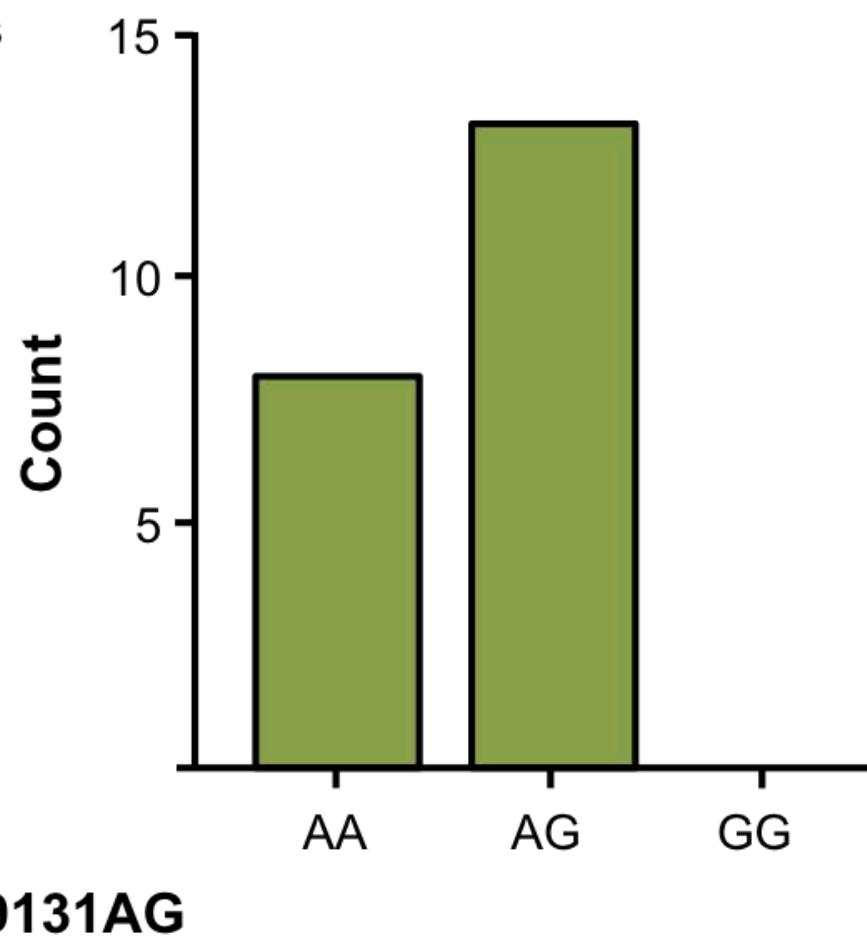




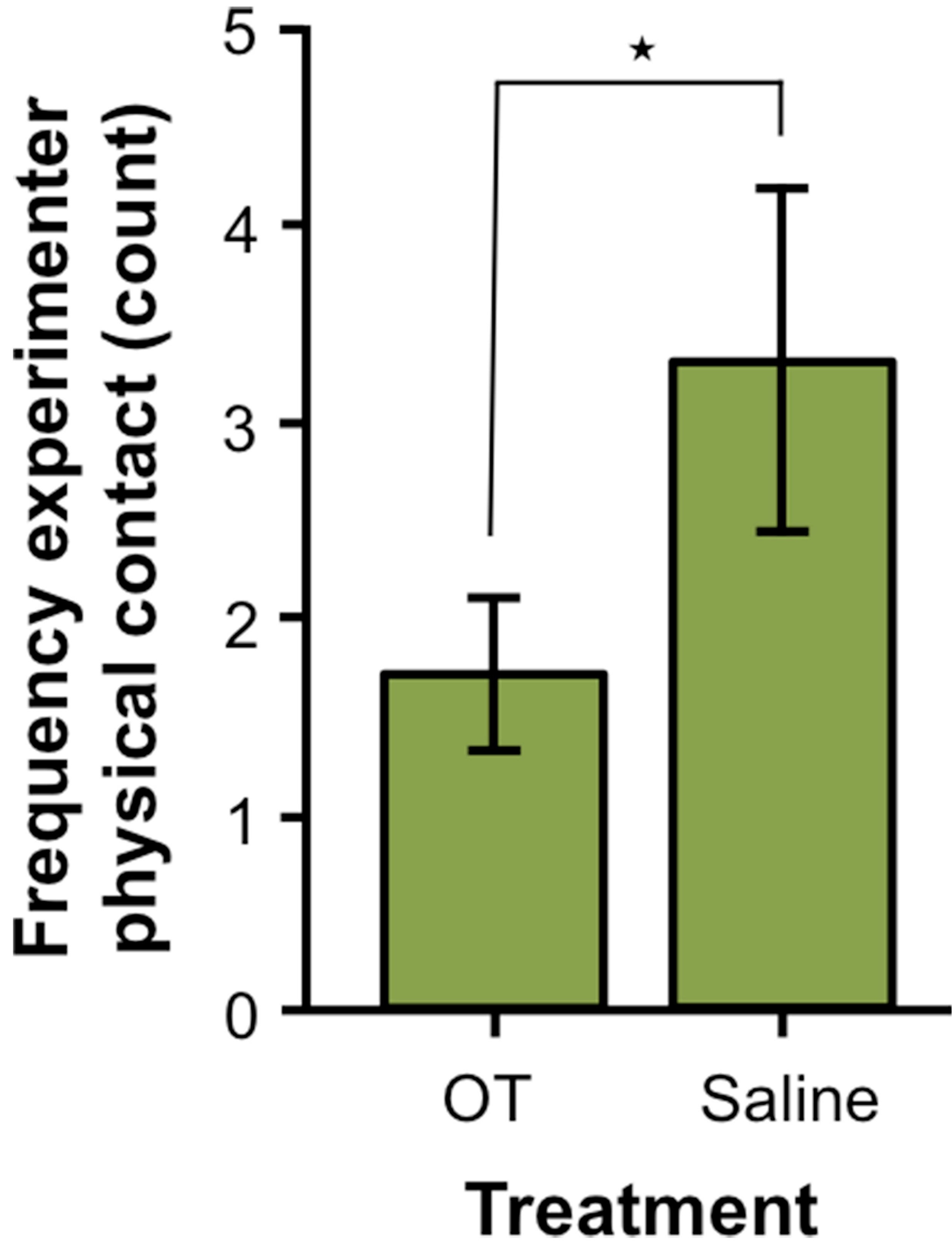




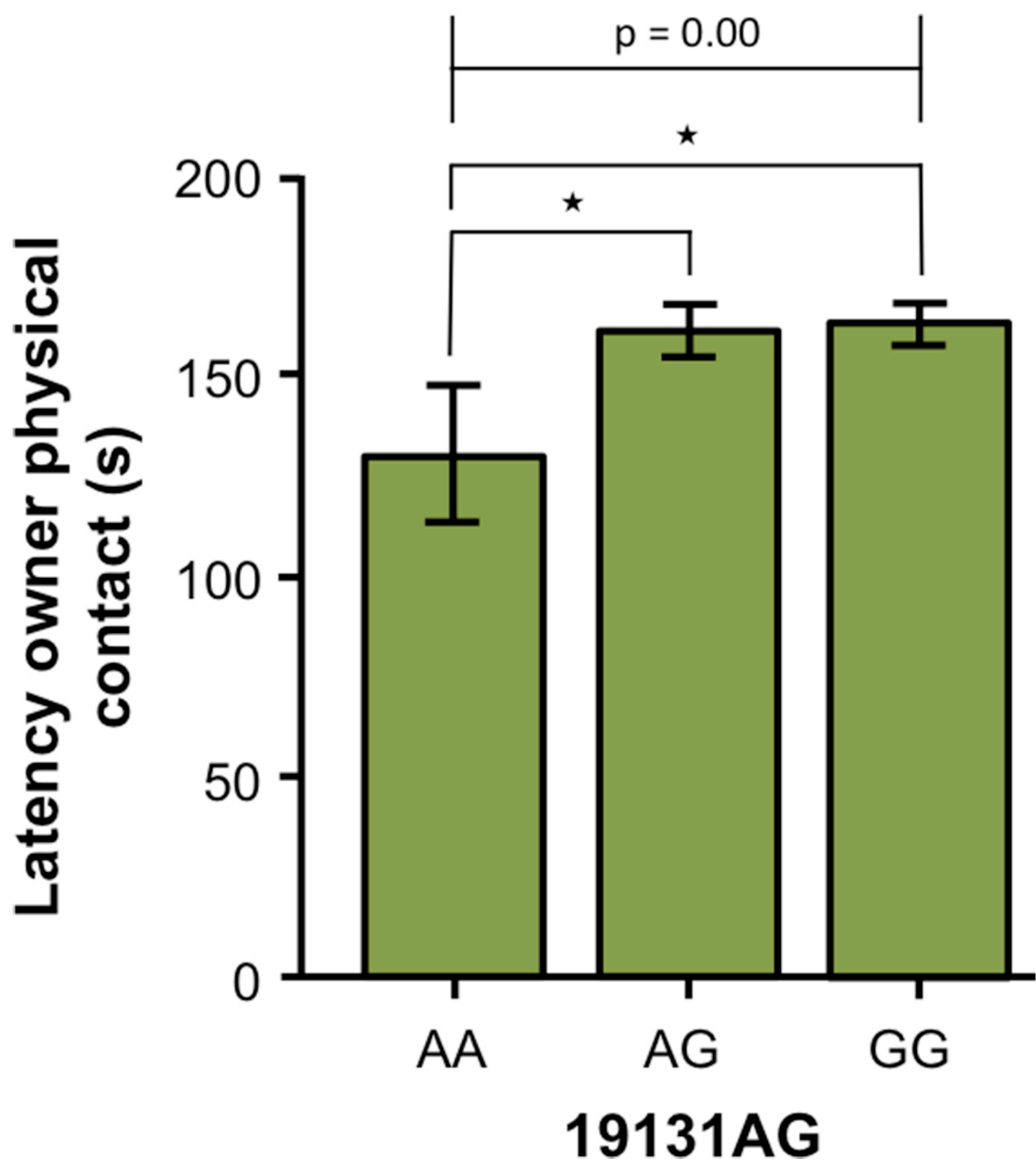




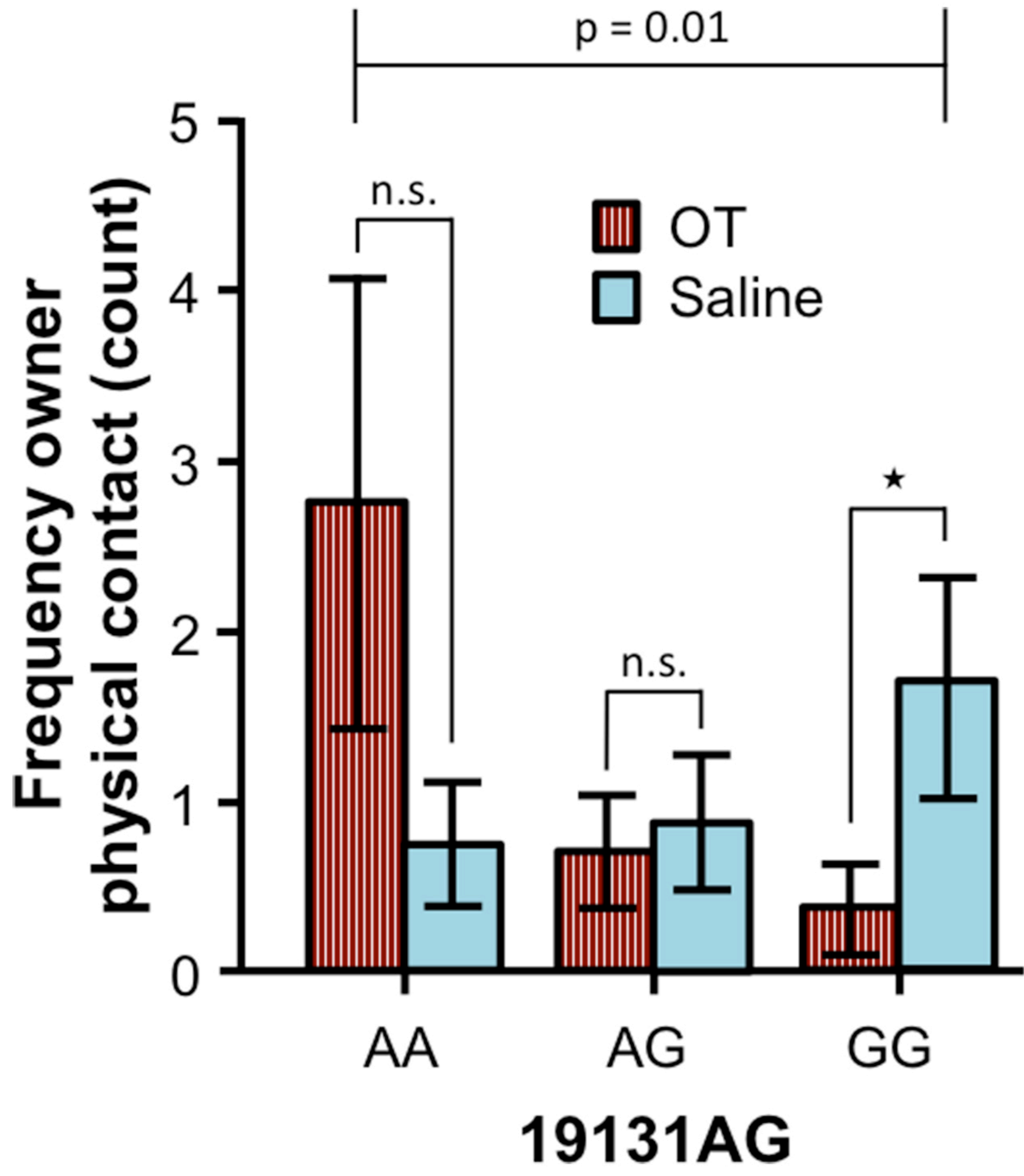




\section{Figure captions}

Oxytocin and a polymorphism in the oxytocin receptor gene are associated with human-directed social behavior in golden retriever dogs

Mia E. Persson, Agaia Trottier, Johan Bélteky, Lina S.V. Roth \& Per Jensen*

Figure 1: A schematic figure of the dog OXTR gene. The region pictured ranges from 9358932 - 9378248 bp starting with a short un-translated region (UTR) (CanFam 3.1). The SNPs genotyped in this current study are marked with red lines at 9359329 bp (-212AG), 9378660 bp (rs8679684) and 9378754 bp (19131AG).

Figure 2: Genotype frequencies of the 19131AG OXTR SNP. Number of dogs (Count) carrying the AA, AG or GG alleles of the SNP out of A) 26 male and 34 female golden retrievers and B) 21 wolves.

Figure 3: Effects of oxytocin treatment (OT) on experimenter physical contact in golden retrievers. Comparison of the mean frequency of physical contact seeking with the experimenter after oxytocin or saline treatment $(\mathrm{p}<$ 0.01 , Cohen's $d=0.47$ ). Error bars show \pm 1 SEM.

Figure 4: Effect of 19131AG OXTR genotype on mean latency to seek owner physical contact. Latency of individuals with the AA-genotype differ significantly from those with the AG-genotype (Bonferroni adjusted $\mathrm{p}<0.01$, Cohen's $d=1.45$ ) and the GG-genotype (Bonferroni adjusted $p<0.01$, Cohen's $d$ 
=1.43). Asteriskes indicate significant difference from the post hoc test $(\mathrm{p}<$ $0.05)$. Error bars display \pm 1 SEM.

Figure 5: Effects of the interaction between 19131AG OXTR genotype and oxytocin treatment (OT) on owner physical contact. Shown is mean frequency of physical contact with the owner and the effects of oxytocin treatment on individuals carrying the AA-genotype (Bonferroni adjusted $\mathrm{p}=$ 0.06, Cohen's $d=0.95$ ) and the GG-genotype (Bonferroni adjusted $\mathrm{p}<0.01$, Cohen's $d=0.81$ ). No significant difference was found for individuals carrying the AG-genotype. Asterisks show post hoc significance $\mathrm{p}<0.05$. Error bars show \pm 1 SEM. 


\author{
Behaviour \\ Duration experimenter \\ Frequency experimenter \\ Latency experimenter \\ Duration experimenter look \\ Frequency experimenter look \\ Latency experimenter look \\ Duration experimenter physical \\ Frequency experimenter physical \\ Latency experimenter physical \\ Duration owner \\ Frequency owner \\ Duration owner look \\ Frequency owner look \\ Latency owner look \\ Duration owner physical \\ Frequency owner physical \\ Latency owner physical \\ Duration Human \\ Frequency Human \\ Duration Look \\ Frequency Look \\ Duration Physical \\ Frequency Physical
}

\begin{tabular}{|c|c|c|}
\hline Akaike & Data LG10 & Distribution \\
\hline \multicolumn{2}{|c|}{197 Sex, treatmer yes } & Normal identity \\
\hline \multicolumn{2}{|c|}{259 Sex, treatmer no } & Gamma log \\
\hline \multicolumn{2}{|c|}{217 Sex, treatmer yes } & Normal identity \\
\hline 132 & Sex yes & Normal identity \\
\hline 280 & Sex & Gamma log \\
\hline \multicolumn{2}{|c|}{206 Sex, treatmer yes } & Normal identity \\
\hline 50 & Treatment yes & Normal identity \\
\hline 109 & Treatment & Normal identity \\
\hline \multicolumn{2}{|c|}{81 Sex, treatmer yes } & Normal identity \\
\hline 190 & Sex yes & Normal identity \\
\hline \multicolumn{2}{|c|}{69 Sex, treatmer yes } & Gamma log \\
\hline \multicolumn{2}{|c|}{164 Sex, treatmer yes } & Gamma log \\
\hline \multicolumn{2}{|c|}{268 Sex, treatmer no } & Gamma log \\
\hline \multicolumn{2}{|c|}{206 Sex, treatmer yes } & Normal identity \\
\hline \multicolumn{2}{|c|}{89 treatment, 1cyes } & Normal identity \\
\hline \multicolumn{2}{|c|}{51 Sex, treatmer yes } & Normal identity \\
\hline & 19131 & Normal identity \\
\hline \multicolumn{2}{|c|}{162 Sex, treatmer yes } & Normal identity \\
\hline \multicolumn{2}{|c|}{48 Sex, treatmer yes } & Normal identity \\
\hline \multicolumn{2}{|c|}{167 Sex, treatmer yes } & Normal identity \\
\hline \multicolumn{2}{|c|}{114 Sex, treatmer yes } & Normal identity \\
\hline \multicolumn{2}{|c|}{139 Sex, treatmer yes } & Normal identity \\
\hline \multicolumn{2}{|c|}{136 19131xtreatr yes } & Normal identity \\
\hline
\end{tabular}




$\begin{array}{llrrrrr} & \text { Sex } & 5.133 & 0.025 & 1 & 118 & 8.13 \\ & \text { Sex } & 7.851 & 0.006 & 1 & 118 & 10.12 \\ \text { Treatment } & & & & & & \\ & & 3.039 & 0.084 & 1 & 118 & 0.89 \\ & \text { Treatment } & 6.533 & 0.012 & 1 & 118 & 1.7 \\ & & & & & & 18.5\end{array}$

$\begin{array}{llrrrrr}\text { Treatment x } 19131 & & 2.501 & 0.087 & 2 & 114 & \\ & & & & & \\ \text { Sex } & & 5.208 & 0.007 & 2 & 113 & \\ & 19131 & 3.596 & 0.06 & 1 & 113 & 129.56\end{array}$


SEM Mean2 (Male/PBS/AG) SEM Mean3 (GG) SEM

$\begin{array}{rrr}1.58 & 3.89 & 0.71 \\ 1.09 & 6.58 & 0.72 \\ & & \\ 0.23 & 1.48 & 0.36 \\ 0.4 & 3.3 & 0.88 \\ & & \\ & & \\ & 32.31 & 5.49\end{array}$

16.58

$160.56 \quad 5.78$

$156.8 \quad 5.9$ 
Behaviour

Duration experimenter

Frequency experimenter

Duration experimenter look

Frequency experimenter look

Frequency owner look

Duration experimenter physical
Significant factor $F$

Occasion

Occasion

Occasion

Occasion

Occasion

First treatment p df1 df2

$\begin{array}{llll}9.909 & 0.002 & 1 & 117\end{array}$

$\begin{array}{llll}6.29 & 0.014 & 1 & 117\end{array}$

$\begin{array}{llll}19.055 & 0 & 1 & 117\end{array}$

$\begin{array}{llll}24.697 & 0 & 1 & 117\end{array}$

$\begin{array}{llll}8.419 & 0.004 & 1 & 117\end{array}$

$\begin{array}{llll}4.867 & 0.029 & 1 & 117\end{array}$ 
Mean1(first occ/OT first) SEM Mean2 (2nd occ/PBS first) SEM

$\begin{array}{rrrr}13 & 1.91 & 19.86 & 2.41 \\ 5.67 & 0.57 & 7.1 & 0.68 \\ 3.52 & 0.57 & 9.06 & 1.78 \\ 5.93 & 0.6 & 11.23 & 1.2 \\ 8.6 & 0.95 & 11.6 & 1.11 \\ 0.7 & 0.23 & 1.7 & 0.37\end{array}$

